\title{
GenetiC VARIABILITY AMONG CERCARIAE OF the SChistosomatidae (Trematoda: Digenea) CAUSing SWIMMER'S ITCH IN EUROPE
}

\author{
PICARD D.* \& JOUSSON O.**
}

\section{Summary :}

Ribosomal DNA sequences of the internal transcribed spacer 1 (ITS1) were obtained from schistosome cercariae responsible for swimmer's itch in Europe. Two types of ITS 1 (1 100 and 1400), which differ by the number of repeated patterns were found among cercariae shedded by Lymnaea ovata and L. auricularia (Lymnaeidae). A phylogenetic analysis of the ITS1 region showed that sequences of each type form two well-defined clades. An adult of Trichobilharzia regenti isolated from the nasal vessels of Anas platyrhynchos (Anatidae) was found to correspond to the cercaria type 1400. The sequencing of several ITSI clones from a single cercaria of each type, as well as a specific PCR-based test suggested that both ITSI types do not co-occur within a single individual.

KEY WORDS : cercarial dermatitis, ribosomal DNA, ITSI, size variation, Trichobilharzia ocellata.

\section{INTRODUCTION}

$\sim$ ercarial dermatitis is a skin allergic response which develops following penetration of larval stages of the trematode family Schistosomatidae. It is considered as an emerging disease in Europe (de Gentile et al., 1996; Chamot et al., 1998). The European infection agents are represented by cercariae of bird schistosomes (Kolarova et al., 1997), whose intermediate hosts are various species of aquatic snails (Dvorak et al., 1999). Five genera of schistosomes parasitizing birds: Dendritobilharzia, Gigantobilharzia, Ornithobilharzia, Bilharziella, and Trichobilharzia have been reported in Europe (Kolarova et al., 1997). The genus Trichobilharzia only was found in France and Switzerland (Eklu-Natey et al. 1985; Gay et al., 1999). The

\footnotetext{
* Laboratoire Génome, Populations, Interactions, CNRS UMR 5000, Université de Montpellier II, F-34095 Montpellier, France.

** Département de Zoologie et Biologie Animale, Université de Genève, CH-1224 Chêne-Bougeries/Geneva, Switzerland.

Correspondence: Olivier Jousson, Département de Zoologie et Biologie Animale, Station de Zoologie, 154 route de Malagnou, CH-1224 Chêne-Bougeries, Switzerland.

Tel.: 0041223498644 - Fax: 0041223492647

E-mail: Olivier.Jousson@zoo.unige.ch
}

Résumé : VARIABILITÉ GÉNÉTIQUe PARMI LES CERCAIRES DE Schistosomatidae (Trematoda: Digenea) Responsables de la DERMATITE DU BAIGNEUR EN EUROPE

Des séquences de la région ITSI (Internal Transcribed Spacer) de I'ADN ribosomique ont été obtenues à partir de cercaires de schistosomes responsables de la dermatite cercarienne en Europe. Deux types d'ITS 1 (1 100 et 1400), qui diffèrent par le nombre de motifs répétés, ont été caractérisés chez des cercaires émises par Lymnaea ovata et L. auricularia (Lymnaeidae). L'analyse phylogénétique de la région ITSI montre que les séquences appartenant à chacun des deux types forment des groupes bien définis. Un ver adulte de Trichobilharzia regenti trouvé dans les vaisseaux nasaux de Anas platyrhynchos (Anatidae) correspond au type cercarien 1400. Le séquençage de plusieurs fragments ITS I clonés à partir d'une cercaire de chaque type, ainsi qu'un test $P C R$ spécifique suggèrent que les deux types d'ITS I ne sont pas présents chez un même individu.

MOTS CLÉS : dermatite cercarienne, ADN ribosomique, ITS1, variation de taille, Trichobilharzia ocellata

type species of this genus is T. ocellata (La Valette, 1855) Brumpt, 1931. The taxonomic status of T. ocellata is not clear and it probably represents a complex of several species (Blair \& Islam, 1983; Kolarova \& Horak, 1996). Recently, several Trichobilharzia species have been described in Europe, including T. szidati Neuhaus, 1952, T. franki Müller \& Kimmig, 1994, and T. regenti Horak, Kolarova \& Dvorak, 1998. A new Trichobilharzia-like cercaria species was recently described from Iceland (Kolarova et al., 1999). Little is known about the natural definitive hosts of Trichobilharzia species; references on findings of $T$. ocellata adults in birds from Russia were presented by Sonin (1985).

Approaches classically used for schistosome species identification are morphological studies, cercarial chaetotaxy (Eklu-Natey et al., 1985; Kolarova \& Horak, 1996), and intermediate host specificity (Odening, 1996). However, in some cases, these approaches may not produce accurate results because the isolation of undamaged adult worms from blood vessels of birds is difficult. It seems that cercarial chaetotaxy may produce variable results, depending on the impregnation conditions of the specimens (Kock \& Böckeler, 1998). As alternative methods, molecular techniques as ribosomal DNA sequencing have proved their efficiency to 
distinguish closely related schistosome species and to establish their phylogenetic relationships (Johnston et al., 1993; Després et al., 1995; Littlewood \& Johnston, 1995; Barker \& Blair, 1996; Blair et al., 1997; Snyder \& Loker, 2000). Similar techniques have also been used to identify the life-cycles of various digeneans by comparing adults and cercariae ribosomal DNA sequences (e.g. Cribb et al., 1998; Jousson et al., 1999). In the present work, we obtained ITS1 ribosomal DNA sequences of schistosome cercariae shedded by two species of Lymnaea snails, L. ovata and L. auricularia (Lymnaeidae) from two subalpine European lakes (lake of Geneva and lake of Annecy) which are characterised by high seasonal accumulations of aquatic birds. Sequences were also obtained from an adult worm of Trichobilharzia regenti isolated from the nasal vessels of Anas platyrhynchos (Anatidae).

\section{MATERIAL AND METHODS}

\section{SAMPLE COLLECTION}

I ndividuals of two species of Lymnaea snails (L. ovata and L. auricularia) were collected in June 2000 from several sites in the lake of Geneva (Switzerland, France) and the lake of Annecy (France). Each Lymnaea individual collected was isolated in a dish filled with filtered freshwater. The dishes were checked twice a day to search for spontaneous emission of schistosomatid cercariae. An adult worm preliminary identified based on microhabitat as T. regenti Horàk, Kolàrovà \& Dvoràk 1998 was isolated from the nasal vessels of Anas platyrhynchos (Anatidae).

\section{DNA EXTRACTION, PCR AMPLIFICATION, CLONING AND SEQUENCING}

DNA was extracted in guanidine lysis buffer, precipitated with isopropanol and dissolved in distilled water. Only single cercariae specimens were used for DNA extraction. The ITS1 region of the ribosomal DNA was amplified using universal primers located at 3 ' end of the $18 \mathrm{~S}$ rDNA (Sbr: 5'-GTAGGTGAACCTGCAGAAGG$\left.3^{\prime}\right)$ and at 5' end of the 5.8S gene (5.8S1: 5'-TGTCGATGAAGAGCGCAGC-3'). PCR amplifications were performed in a total volume of $50 \mu \mathrm{l}$ with an amplification profile consisting of 40 cycles of $30 \mathrm{~s}$ at $94^{\circ} \mathrm{C}$, $30 \mathrm{~s}$ at $52^{\circ} \mathrm{C}$ and $120 \mathrm{~s}$ at $72^{\circ} \mathrm{C}$, followed by $5 \mathrm{~min}$ at $72^{\circ} \mathrm{C}$ for final extension. Amplified PCR products were purified using the High Pure PCR Purification Kit (Roche Diagnostics). Most of the PCR products were sequenced directly using amplification primers. Additionally, amplified fragments of types 1100 and 1400 were ligated in the p-GEM-T Vector (Promega) and cloned in the XL-2 Ultracompetent Cells (Stratagene).
Several colonies from each culture were sequenced in order to test the occurrence of intra-individual polymorphism. All DNA sequences were obtained using an ABI377 automated DNA sequencer (Perkin-Elmer). A PCR test was subsequently developed to distinguish ITS1 types 1100 and 1400 , using the universal reverse primer 5.8S1 and specific forward primers (spec-1100: 5'-CATTCATAAAGAACTGTT-3' and spec-1400: 5'-CGCAGTCAATCATTCAAACTG-3') designed along ITS1 sequences.

\section{SEQUENCE ANALYSIS}

The sequences were aligned manually using the program GDE 2.2 (Larsen et al., 1993) and analysed using the following methods: the neighbor-joining (NJ) method (Saitou \& Nei, 1987) using Kimura two-parameters distance, the maximum parsimony (MP) method, using heuristic search with the branch-swapping option included in PAUP* (Swofford, 1998) and the maximum likelihood (ML) method with a transitions-transversions ratio of 2, as implemented in the fast DNAml program (Olsen et al., 1994). The reliability of internal branches was assessed using the bootstrap method (Felsenstein, 1988). The PHYLO_WIN program (Galtier \& Gouy, 1996) was used for distance computations, NJ and ML tree building and bootstraping. DNA sequences analysed in this study have been deposited in the EMBL-GenBank database under accession numbers AJ312041-AJ312049.

\section{RESULTS}

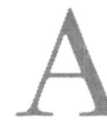

mong 2,755 individuals of L. ovata and 249 individuals of $L$. auricularia collected, respectively $56(2.03 \%)$ and two $(0.80 \%)$ were infected by schistosomatids. Polymerase chain reaction amplification of the ITS1 rDNA region from schistosomatid cercariae gives a single product of the length 1100 or $1400 \mathrm{bp}$. Two cercariae isolated from two individuals of L. auricularia, as well as four cercariae isolated from four individuals of $L$. ovata generated a PCR product of $1100 \mathrm{bp}$. The adult of $T$. regenti, as well as two cercariae isolated from two individuals of $L$. ovata generated a PCR product of $1400 \mathrm{bp}$. The subsequent sequencing of amplified fragments showed that these differences are due to the presence of a variable number of repeated patterns in the ITS1. There are three kinds of subrepeats (a: 75 bp; b: 30 bp; c: 40 bp) (Fig. 1). The structure of repeated patterns of cercariae type 1100 isolated from $L$. ovata and L. auricularia is of type $b(a b)_{3}$. The cercariae type 1400 isolated from $L$. ovata and the adult of $T$. regenti harbour six repeat clusters of type ba-(ca) $)_{5}$. The variation among repeated patterns reaches 15 nucleotide substitutions (15.1\%) within cercariae type 1100 isolated from both snail host species (Fig. 2). The variation between 


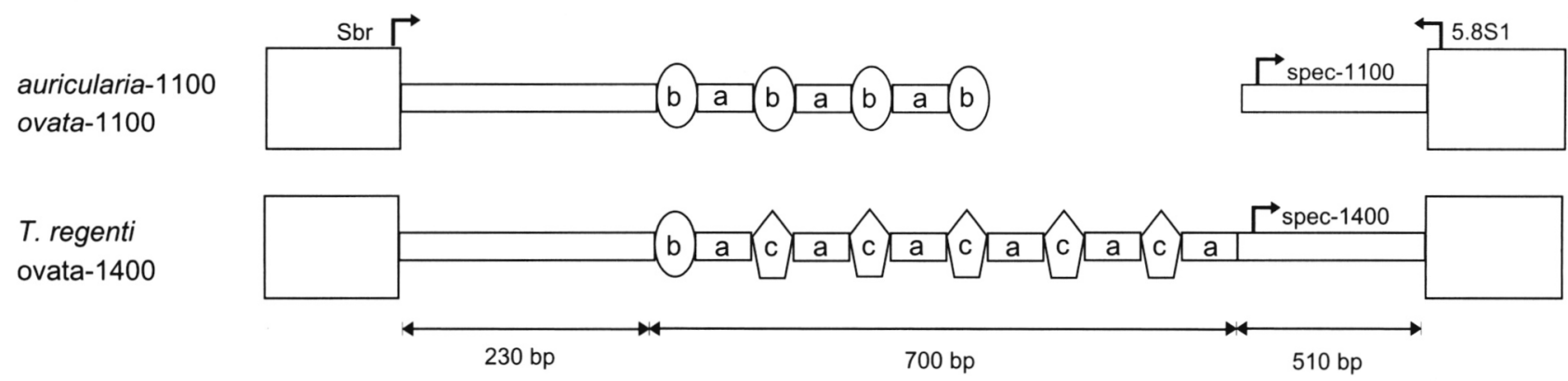

Fig. 1. - Schematic representation of the ITS1 ribosomal DNA types of analysed material. auricularia-1100 and ovata-1100: 1100 bp ITS1 type of cercariae shedded by L. auricularia and L. ovata; T. regenti and ovata-1400: 1400 bp ITS1 type of an adult of T. regenti and a cercaria shedded by L. ovata. Position of universal (Sbr, 5.8S1) and specific (spec-1100, spec-1400) amplification primers are indicated. The lengths of repeated patterns are: a: 75 bp; b: 30 bp; c: 40 bp.

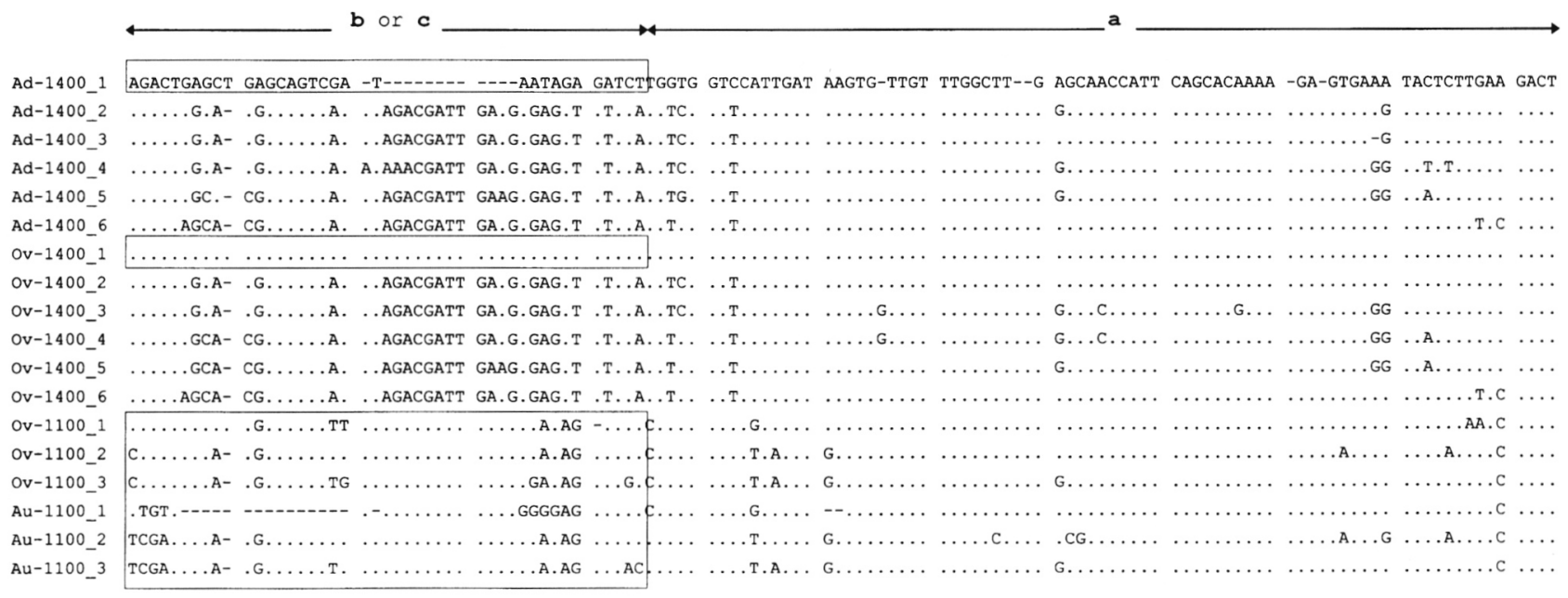

Fig. 2. - Alignment of ITS1 repeats within three schistosomatid cercariae (ovata-1400, ovata-1100, and auricularia-1100) and an adult (T. regenti) shown in figure 1. "." indicates the same base as shown on upper line; "-" indicates alignment gaps. The position of repeated patterns (a, b, c) is indicated. Sequences inside boxes correspond to the pattern "b", which is partially deleted in the first repeat of the cercaria shedded by L. auricularia (Au-1100_1). Ad-1400_1-6: ITS1 repeats from an adult of T. regenti infecting Anas platyrbynchos; Ov1400_1-6: ITS1 repeats from a cercaria type 1400 shedded by L. ovata; Ov-1100_1-3: ITS1 repeats from a cercaria type 1100 shedded by L. ovata; Au-1100_1-3: ITS1 repeats from cercaria type 1100 shedded by L. auricularia.

repeats occurring in type 1400 reaches 24 substitutions (22.4\%) if all copies are included, and 12 substitutions $(10.2 \%)$ if the first pattern "b" is removed.

The aligned data set of ITS1 sequences comprises 1,271 sites. When all gaps are removed, there remains 811 sites, of which 89 are variable (11.0\%) and 66 informative $(8.1 \%)$. The phylogenetic analysis of ITS1 sequences using MP, NJ and ML methods shows the occurrence of two clades including all sequences of each type (Fig. 3). The sequence divergence between types 1100 and 1400 reaches $11 \%$ (89 substitutions), whereas the within-type divergence reaches $5.6 \%$ (47 substitutions) for the type 1100, and $1.8 \%$ (16 substitutions) for the type 1400. The cloning of several ITS1 from single isolates showed a very low level of intraindividual variation, which does not exceed $0.6 \%$ for the type 1100 and $1.0 \%$ for the type 1400 . To determine if the closely related ITS1 types 1100 and 1400 could be present within a single DNA extraction, we amplified DNA from single cercaria of both types using specific primers designed in the 3 ' part of ITS1 (Fig. 1). We obtained positive amplifications using the specific primer spec-1100 only for the type 1100 (Fig. 4, lane 2), and primer spec-1400 only for the type 1400 (Fig. 4, lane 6). This would suggest that both types do not co-occur within a single cercaria.

\section{DISCUSSION}

T The present study is the first attempt to establish the degree of genetic variability among schistosomatid cercariae causing swimmer's itch in 
Fig. 3. - Phylogenetic tree of cercariae analysed in this study and one adult ( T. regenti) inferred from ITS1 ribosomal DNA sequences by using the Maximum Parsimony (MP) method with the heuristic search option. All nodes supported by bootstrap values lower than $50 \%$ were collapsed into a polytomy. Bootstrap values are given for $\mathrm{MP} / \mathrm{NJ} / \mathrm{ML}$ methods. Sequences belonging to each of the two types of ITS1 are shown inside boxes. Snail hosts are ov: L. ovata; auri: L. auricularia. Sequences obtained from cloned ITS1 fragments are indicated.

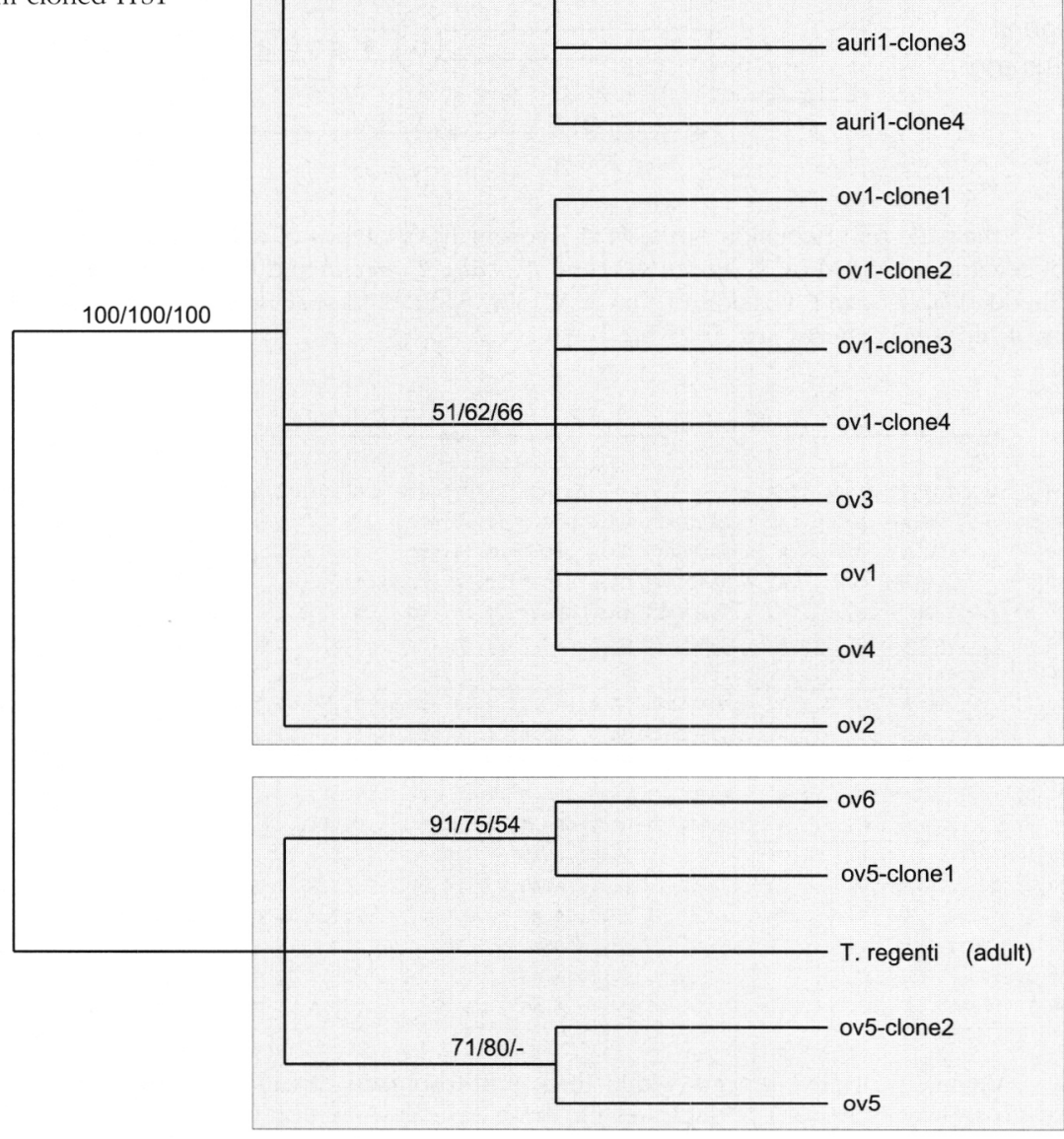

Europe. ITS1 ribosomal DNA sequences obtained from cercariae produced by Lymnaea ovata and L. auricularia showed the occurrence of two distinct genotypes (type 1100 and type 1400) which differ by the number of repeated patterns. In the Digenea, such a kind of ITS1 variability has been previously observed within and among individuals of Dolichosaccus (Luton et al., 1992), Paragonimus (van Herwerden et al., 1999) and Schistosoma species (Kane \& Rollinson, 1994; Kane et al., 1996; van Herwerden et al., 1998; 1999). These authors observed the occurrence of different ITS1 variants within a single individual and suggested that it could be due to the occurrence of differences in rates of concerted evolution among repetitive ribosomal genes. We tested the hypothesis of the presence of several ITS1 types within a single cercaria by sequencing several ITS1 cloned fragments (Fig. 3), as well as by using a specific PCR test (Fig. 4). These approaches did not reveal the presence of both types within a single individual. This would suggest that the two ITS1 types found represent distinct entities. Our data reveal that cercariae of type 1100 are parasitizing the two intermediate host species. This is in contradiction with the apparent strict intermediate host specificity of European Trichobilharzia species (Müller \& Kimmig, 1994; Horak et al., 1998). Further studies based on significant number of host and parasite samples will show if both cercariae types may occur in L. ovata and L. auricularia. There is a high genetic similarity between the cercariae of type 1400 and the adult of $T$. regenti. Further work, particularly the comparison with ITS sequences of unambiguously identified adult specimens is required to determine with more accuracy if both cercaria types really correspond to distinct species. This may help to have a better knowledge of host-parasite associations and resolve the life histories of Trichobilharzia species in Europe. 

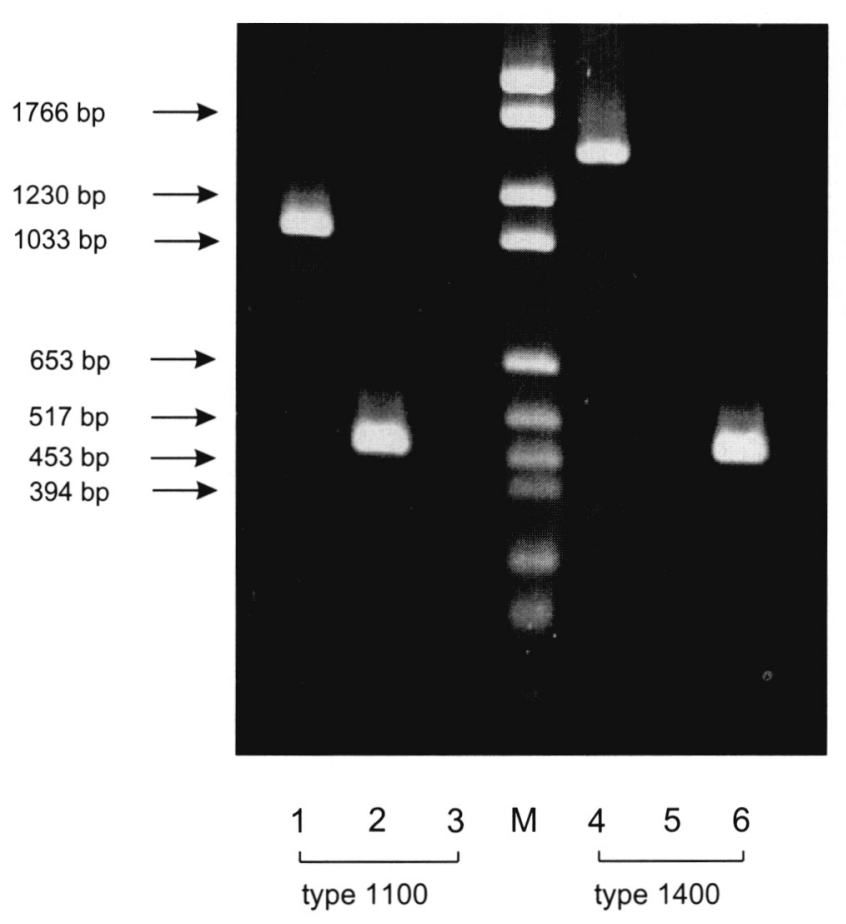

Fig. 4. - PCR amplifications of cercariae types 1100 (lanes 1-3) and 1400 (lanes 4-6). Primers used are: lanes 1 and 4: Sbr-5.8S1 (universal); lanes 2 and 5: specific 1100-5.8S1; lanes 3 and 6: specific 1400-5.8S1. M: Molecular weight marker.

\section{ACKNOWLEDGEMENTS}

W

e thank Jean-Paul Dubois, Cyrille Hubert (INRA Thonon) and Jacques Mouthon (CEMAGREF Lyon) for their help in collecting and identifying the snail hosts. We are indebted to Vasyl Tkach, Jan Pawlowski, Libuse Kolarova and Petr Horak for fruitful comments and discussion. We also thank José Fahrni for sequencing assistance, and François Bonhomme, Patrick Silan (Laboratoire Génome, Populations, Interactions, CNRS UMR 5000, Montpellier) to have provided a part of the financial support of this study.

\section{REFERENCES}

BARKER S.C. \& BLAIR D. Molecular phylogeny of Schistosoma species supports traditional groupings within the genus. Journal of Parasitology, 1996, 82 (2), 292-298.

Blair D. \& IsLam K.S. The life-cycle and morphology of Trichobilharzia australis n. sp. (Digenea: Schistosomatidae) from the nasal blood vessels of the black duck (Anas superciliosa) in Australia, with a review of the genus Trichobilharzia. Systematic Parasitology, 1983, 5, 89-117.

Blair D., van Herwerden l., Hirai H., Taguchi T., Habe S., Hirata M., Lai K., Upatham S. \& Agatsuma T. Relationships between Schistosoma malayensis and other Asian schis- tosomes deduced from DNA sequences. Molecular and Biochemical Parasitology, 1997, 85, 259-263.

Chamot E., Toscani L. \& Rougemont A. Public health importance and risk factors for cercarial dermatitis associated with swimming in Lake Leman at Geneva, Switzerland. Epidemiological Infections, 1998, 120, 305-314.

Cribb T.H., Anderson G.R., Adlard R.D. \& Bray R.A. A DNAbased demonstration of a three-host life-cycle for the Bivesiculidae (Platyhelminthes, Digenea). International Journal for Parasitology, 1998, 28, 1791-1795.

de Gentile L., Picot H., Bourdeau P., Kerjan A., Piriou M., Le Guennic A., Bayssade-Dufour C., Chabasse D. \& MotT K.E. La dermatite cercarienne en Europe: un problème de santé publique nouveau? Bulletin de l'OMS, 1996, 74, 159163.

Després L., Kruger F.J., Imbert-Establet D. \& Adamson M.L. ITS2 ribosomal DNA indicates Schistosoma hippopotami is a distinct species. International Journal for Parasitology, 1995, 25, 1509-1514.

Dvorak J., Sattmann H., Horak P. \& Konecny R. Bird schistosomes from freshwater snails in Austria, with some notes on current problems (Digenea, Schistosomatidae). Tropenmedical Parasitology, 1999, 21, 69-76.

Eklu-Natey D., Al-Khudri M., Gauthey D., Dubois J.P., WÜEst J., Vaucher C. \& Huggel H. Épidémiologie de la dermatite des baigneurs et morphologie de Trichobilharzia cf. ocellata dans le lac Léman. Revue Suisse de Zoologie, 1985, 92, 939-953.

Felsenstein J. Phylogenies from molecular sequences: inference and reliability. Annual Review of Genetics, 1988, 22, 521-565.

Galtier N. \& Gouy M. SEAVIEW and PHYLO_WIN: two graphic tools for sequence alignment and molecular phylogeny. Computer Applications in the Biosciences, 1996, 12, 543-548.

Gay P., Bayssade-Dufour C., Grenouillet F., Bourezane Y. \& Dubois J.P. Étude expérimentale de dermatites cercariennes par Trichobilharzia en France. Médecine et Maladies Infectieuses, 1999, 29, 629-637.

Horak P., Kolarova L. \& DVORAK J. Trichobilharzia regenti n. sp. (Schistosomatidae, Bilharziellinae), a new nasal schistosome from Europe. Parasite, 1998, 5, 349-357.

Johnston D.A., Dias Neto E., Simpson A.J.G. \& Rollinson D. Opening the can of worms: molecular analysis of schistosome populations. Parasitology Today, 1993, 8, 286-291.

Jousson O., BARTOLI P. \& PAWLOWSKI J. Molecular identification of developmental stages in Opecoelidae (Digenea). International Journal for Parasitology, 1999, 29, 18531858.

KANE R.A. \& Rollinson D. Repetitive sequences in the rDNA internal transcribed spacer of Schistosoma haematobium, Schistosoma intercalatum and Schistosoma mattheei. Molecular and Biochemical Parasitology, 1994, 63, 153-156.

Kane R.A., Ridgers I.L., Johnston D.A. \& Rollinson D. Repetitive sequences within the first internal transcribed spacer of ribosomal DNA in schistosomes contain a Chi-like site. Molecular and Biochemical Parasitology, 1996, 75, 265269. 
KOCK S. \& BÖCKELER W. Observations on cercarial chaetotaxy as a means for the identification of European species of Trichobilharzia Skrjabin and Zakharow, 1920 (Digenea: Schistosomatidae). Systematic Parasitology, 1998, 43, 159-166.

Kolarova L. \& HoraK P. Morphology and chaetotaxy of Trichobilharzia szidati Neuhaus, 1952 cercariae (Trematoda: Schistosomatidae: Bilharziellinae). Helminthologia, 1996, 33, 3-7.

Kolarova L., HoraK P. \& SitKo J. Cercarial dermatitis in focus: schistosomes in the Czech Republic. Helminthologia, 1997, 34 (3), 127-139.

Kolarova L., Skirnisson K. \& HoraK P. Schistosome cercariae as the causative agent of swimmer's itch in Iceland. Journal of Helminthology, 1999, 73, 215-220.

Larsen N., Osen G.J., Maidak B.L., Mc Caughey M.J., OverBeEK R., Macke T.J., Marsh T.L. \& Woese C.R. The ribosomal database project. Nucleic Acids Research, 1993, 21, 3021-3023.

LITTLEWOOD D.T.J. \& JOHNSTON D.A. Molecular phylogenies of the four Schistosoma species groups determined with partial $28 \mathrm{~S}$ ribosomal RNA gene sequences. Parasitology, 1995, 111, 167-175.

LUTON K., WALKER D. \& Blair D. Comparison of ribosomal internal transcribed spacers from two congeneric species of flukes (Platyhelminthes: Trematoda: Digenea). Molecular and Biochemical Parasitology, 1992, 56, 323-328.

Müller V. \& Kimmig P. Trichobilharzia franki n. sp.-die Ursache für Badedermatitiden in Südwestdeutschen Baggerseen. Applied Parasitology, 1994, 35, 12-31.

ODENING K. What Cercaria ocellata actually is. Acta Parasitologica Turc., 1996, 20 (1), 387-397.

Olsen G.J., Matsuda H., Hagstrom R. \& Overbeek R. Fast DNAm1: a tool for construction of phylogenetics trees of DNA sequences using maximum likelihood. Computer Applications in the Biosciences, 1994, 10, 41-48.

SAITOU N. \& NeI M. The Neighbor-Joining method: a new method for reconstructing phylogenetic trees. Molecular Biology and Evolution, 1987, 4, 406-425.

SONIN M.D. Key to the determination of trematodes infecting fisheating birds in the Palearctic region. Publishing House AN SSSR Moscow, 1985, 440 pp.

SNYDER S.D. \& LOKER E.S. Evolutionary relationships among the Schistosomatidae (Platyhelminthes: Digenea) and an asian origin for Schistosoma. Journal of Parasitology, 2000, 86 (2), 283-288.

SwOFFORD D.L. PAUP*: phylogenetic analysis using parsimony, version 4.0b2a. Sinauer Associates, Sunderland, Mass, 1998.

van Herwerden L., Blair D. \& Agatsuma T. Intra- and interspecific variation in nuclear ribosomal internal trancribed spacer 1 of the Scbistosoma japonicum species complex. Parasitology, 1998, 116, 311-317.

van Herwerden L., Blair D. \& Agatsuma T. Intra- and interindividual variation in ITS1 of Paragonimus westermani (Trematoda: Digenea) and related species: implications for phylogenetic studies. Molecular Phylogenetics and Evolution, 1999, 12 (1), 67-73.

Reçu le 19 février 2001

Accepté le 12 juin 2001 